\title{
An Uncommon Presentation of Erythrodermic Psoriasis in a Patient Without a History of Psoriasis
}

\author{
Matt Rendo ${ }^{1}$, Joshua Boster ${ }^{1}$, Scott R. Dalton ${ }^{2}$, Heather Yun ${ }^{1}$ \\ 1. Internal Medicine, Brooke Army Medical Center, Fort Sam Houston, USA 2. Pathology and \\ Dermatology, Brooke Army Medical Center, Fort Sam Houston, USA
}

$\square$ Corresponding author: Matt Rendo, joshb003@yahoo.com

Disclosures can be found in Additional Information at the end of the article

\section{Abstract}

Erythrodermic psoriasis is a rare and potentially fatal skin condition. We present the case of a 68-year-old woman, with no prior dermatologic history, who was treated with steroid injection for an insect bite one month prior to presentation and subsequently developed a diffuse erythematous rash. She presented to a military medical center in shock, with weeping, coalesced plaques covering the majority of her skin. Skin biopsies revealed pustular psoriasis, and treatment with infliximab was initiated for erythrodermic psoriasis. After six weeks and three infliximab infusions, the cutaneous lesions had nearly completely resolved.

Categories: Dermatology, Internal Medicine

Keywords: erythroderma, psoriasis, infliximab

\section{Introduction}

Erythrodermic psoriasis (EP) is a rare, severe form of plaque psoriasis with the sudden development of inflammatory, erythematous skin plaques and edema. Diagnosis requires the involvement of over $75 \%$ of the total body surface area (TBSA) and may lead to metabolic and systemic compromise [1]. Untreated, the patient may succumb to multisystem organ failure and high output heart failure secondary to cutaneous volume loss [2]. We present a case of EP as a patient's first presentation of psoriasis late in life.

\section{Case Presentation}

Received 02/19/2019

Review began 06/19/2019 Review ended 07/07/2019 Published 07/08/2019

๑) Copyright 2019

Rendo et al. This is an open access article distributed under the terms of the Creative Commons Attribution License CC-BY 3.0., which permits unrestricted use, distribution, and reproduction in any medium, provided the original author and source are credited.
The patient is a 68-year-old morbidly obese female who developed a papulosquamous eruption under her breast one month after receiving a solumedrol injection for a presumed insect bite. Over one week, the rash spread to involve large areas of the trunk, proximal extremities, and scalp.

A skin biopsy performed in the clinic revealed psoriasiform dermatitis involving $40 \%$ of her TBSA. Topical triamcinolone cream was initiated. Two weeks later, she presented to the emergency room in shock with tachycardia, hypotension, diffuse skin pain, leukocytosis, and acute kidney injury. She had weeping, coalescing violaceous plaques and erosions on the chest, abdomen, back, and upper and lower extremities involving greater than 90\% TBSA (Figure 1). There were pustules scattered across discrete plaques on the bilateral lower extremities. With no identifiable triggers or personal or family history of psoriasis, empiric antibiotic coverage with clindamycin and topical miconazole was initiated for a possible superinfection. A tuberculin skin test, chest X-ray, human immunodeficiency virus (HIV) test, and hepatitis 


\section{Cureus}

panels were unremarkable. Dermatology was consulted, and she was continued on triamcinolone cream with wet skin wraps. Her acute kidney injury resolved with intravenous (IV) fluids, and she developed diffuse edema in the setting of continued weeping plaques. The pustules on her legs formed vesicles prior to rupturing with a gradual coalescence of the diffuse erythematous plaques.
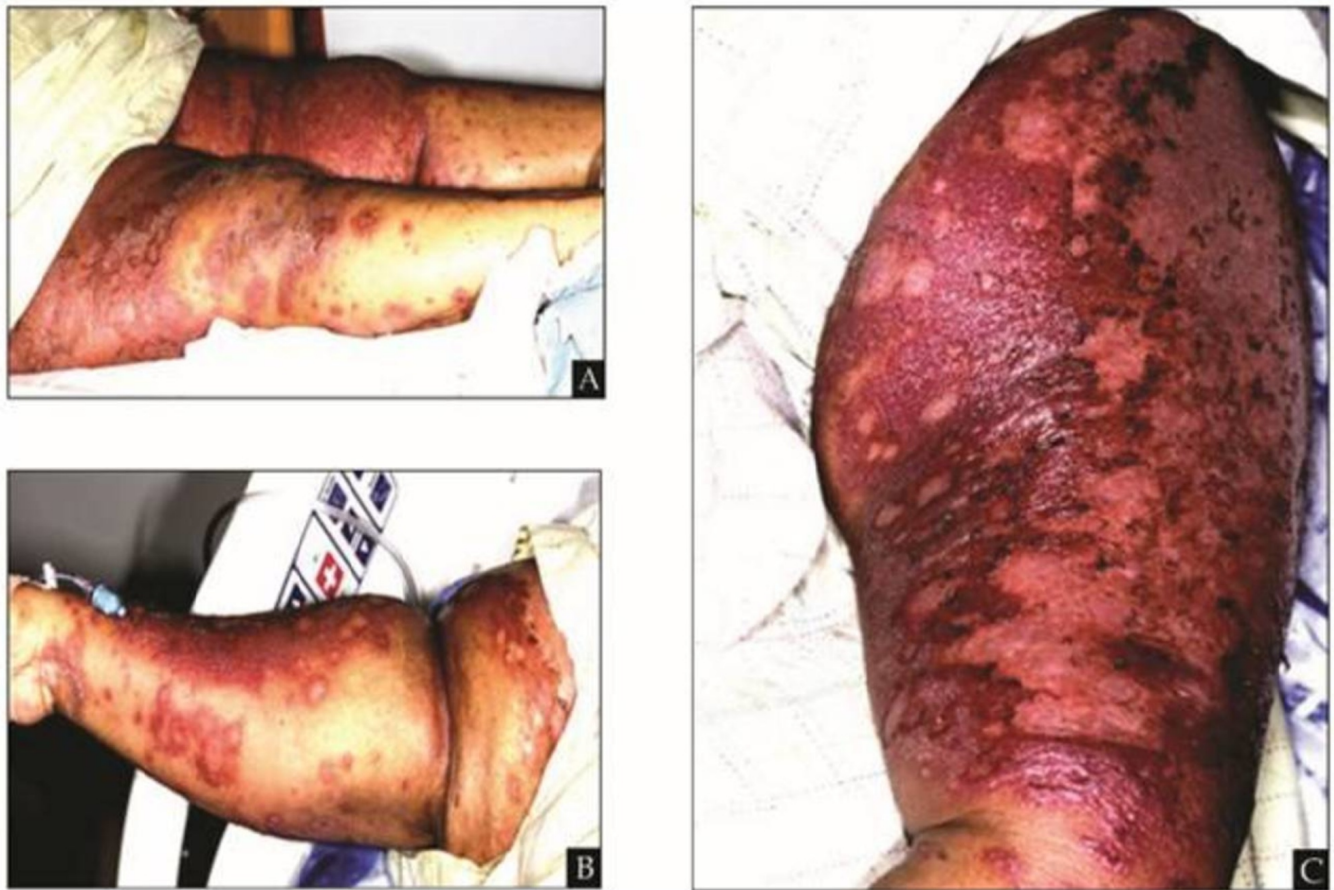

FIGURE 1: Bilateral proximal lower extremities with near complete plaque confluence with various sizes and states of plaque development on the distal lower extremities (A). Right forearm with scattered plaques coalescing on the lateral aspect of the forearm (B). Left forearm with near complete violaceous plaque confluence (C).

Direct immunofluorescence was negative for immunoglobulin (Ig) G, IgA, IgM, and fibrin along the dermal-epidermal junction without evidence of IgA pemphigus. Repeat skin biopsy returned as pustular psoriasis (Figure 2). The patient was started on infliximab infusions. After the third infusion six weeks later, she had 10\% TBSA still affected and was nearly lesion-free after five months. 


\section{Cureus}
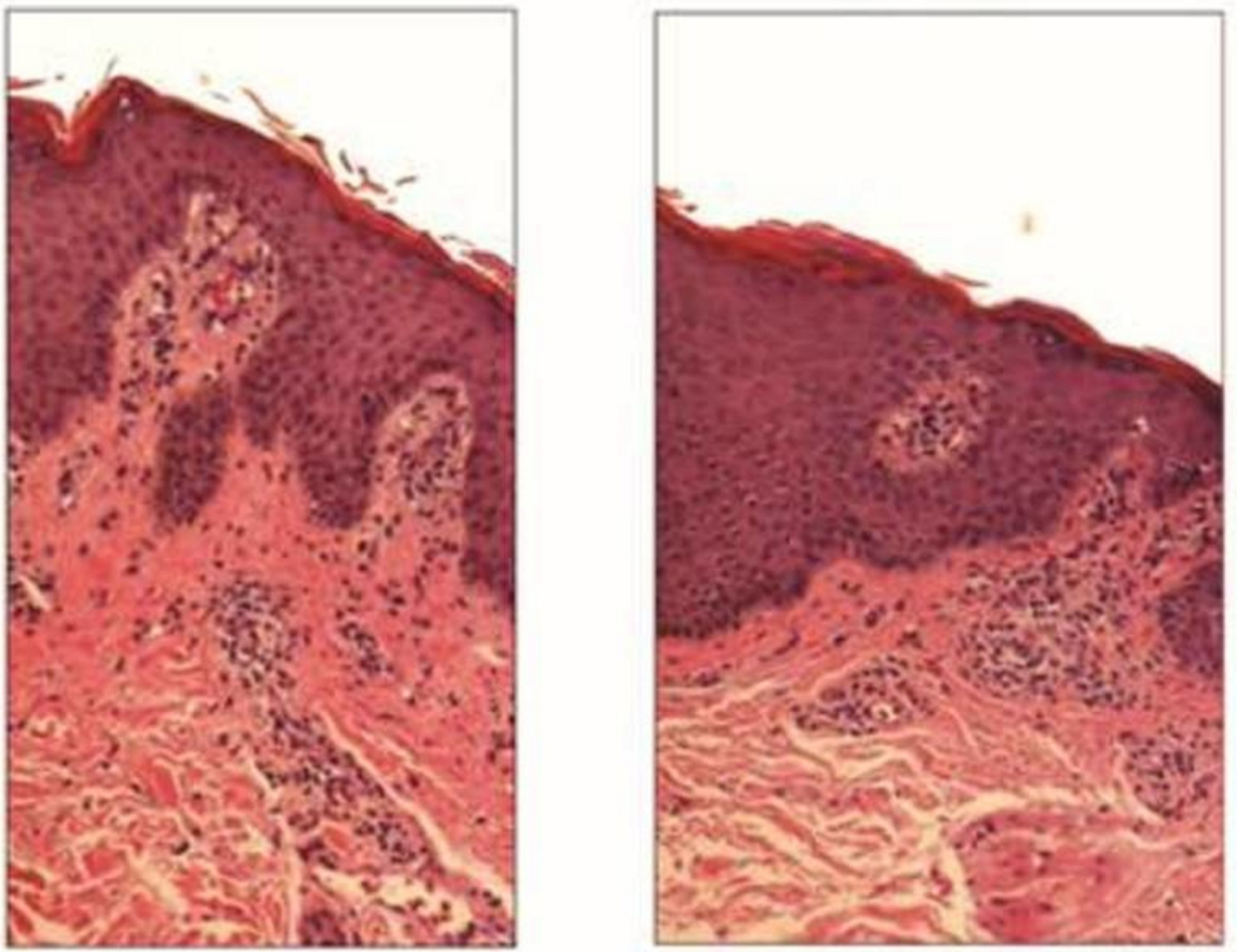

\section{FIGURE 2: Skin biopsy illustrating psoriatic changes. Superficial perivascular lymphocytic infiltrate.}

The overlying epidermis shows regular psoriaform epidermal hyperplasia with thinning of the suprapapillary plates and dilated telangiectatic vessels in the papillary dermis. There is a loss of the granular cell layer in areas and neutrophils are present in the stratum corneum. Hematoxylin-eosin, original magnification $\times 40$.

\section{Discussion}

EP is a rare and potentially fatal variant of plaque psoriasis believed to affect less than $3 \%$ of patients with psoriasis [3]. The majority of patients require hospitalization for fluid and electrolyte replacement in addition to assistance with wound care. Common etiologies for patients presenting with erythroderma include exacerbations of previous existing dermatosis, hypersensitivity drug reactions, and hematologic and cutaneous malignancies [4]. In 30\% of cases, the etiology remains elusive. Furthermore, risk factors for the development of EP include a personal or family history of psoriasis, exposure to immunosuppressive medications, particularly systemic glucocorticoids, and HIV infection. With a broad differential diagnosis and no previous history of psoriasis, the diagnosis of EP in this patient was particularly challenging.

EP can be difficult to diagnose based on histopathology alone, and the clinical features often assist in determining the underlying cause. Notably, parakeratosis, acanthosis, and psoriasiform hyperplasia do not always indicate underlining psoriasis. This patient presented originally to an outpatient provider with concerns for an insect bite under her left breast described as a papulosquamous eruption. She received a steroid injection without clinical improvement. Subsequently, the rash rapidly progressed to cover over $90 \%$ of her body and prompted presentation to the emergency room. We presume that the initial insect bite was the first sign of psoriasis, which developed into EP in the setting of corticosteroid withdrawal. In 
this case, a correlation of subtle pathology and clinical history led to the diagnosis of EP.

Treatment for EP includes adequate hydration, topical steroids and vitamin D analogs, management of associated infections, and immunosuppression for uncontrolled symptoms [5]. Cyclosporine is the drug of choice for EP. With cyclosporine's association with nephrotoxicity, infliximab is often used in patients with renal disease or hypertension [5-7]. While there are no head-to-head trials comparing biologic therapy in patients with EP, over half are treated with infliximab [6]. After five months of treatment, this patient was nearly lesion free.

\section{Conclusions}

This case represents an unusual presentation of EP in a patient without a prior history of psoriasis. When patients present critically ill with an erythrodermic rash, it is important to consider EP in the differential diagnosis, especially in the setting of a recent withdrawal of immunosuppression or steroid use. Skin biopsy and histological analysis aids in the diagnosis of EP given the broad differential associated with erythrodermic skin reactions. In this patient, treatment with infliximab resulted in rapid clinical improvement.

\section{Additional Information}

\section{Disclosures}

Human subjects: Consent was obtained by all participants in this study. Conflicts of interest: In compliance with the ICMJE uniform disclosure form, all authors declare the following: Payment/services info: All authors have declared that no financial support was received from any organization for the submitted work. Financial relationships: All authors have declared that they have no financial relationships at present or within the previous three years with any organizations that might have an interest in the submitted work. Other relationships: All authors have declared that there are no other relationships or activities that could appear to have influenced the submitted work.

\section{Acknowledgements}

We thank Kayla Boster for her expertise in the development of the images used in this manuscript. The views expressed are solely those of the authors and do not reflect the official policy or position of the US Army, US Navy, US Air Force, Department of Defense, or the US Government.

\section{References}

1. Kanthraj GR, Srinivas CR, Uma Devi P, et al.: Quantitative estimation and recommendations for supplementation of protein lost through scaling exfoliative dermatitis. Int J Dermatol. 1999, 38:91-95. 10.1046/j.1365-4362.1999.00408.x

2. Voigt G, Kronthal H, Crounse R: Cardiac output in erythrodermic skin disease . Am Heart J. 1966, 72:615-620. 10.1016/0002-8703(66)90344-9

3. Lebwhol M: Psoriasis. Lancet. 2003, 361:1197-204. 10.1016/S0140-6736(03)12954-6

4. Green M, Prystowsky JH, Cohen SR, Cohen JI, Lebwohl MG: Infectious complications of erythrodermic psoriasis. J Am Acad Dermatol. 1996, 345:911-914. 10.1016/S01909622(96)90078-X

5. Rosenbach M, Hsu S, Korman NJ, Lebwohl MG, Young M, Bebo BF Jr, Van Voorhees AS: Treatment of erythrodermic psoriasis: from the medical board of the National Psoriasis Foundation. J Am Acad Dermatol. 2010, 62:655-662. 10.1016/j.jaad.2009.05.048

6. Levin E, Debbaneh M, Koo J, Liao W: Biologic therapy in erythrodermic psoriasis . J Drugs Dermatol. 2014, 13:342-354.

7. Takahashi MD, Castro LG, Romiti R: Infliximab as sole or combined therapy, induces rapid clearing of erythrodermic psoriasis. Br J Dermatol. 2007, $157: 828-831.10 .1111 /$ j.1365- 


\section{Cureus}

2133.2007.08111.x 